Reseña: Han, Byung-Chul, Ausencia. Acerca de la cultura y la filosofía del Lejano Oriente, Buenos Aires, Caja Negra, 2019.

\title{
Maximiliano Garbarino*
}

Byung-Chul Han es conocido por su prolífica obra en el campo de la crítica cultural de las sociedades contemporáneas. También es conocida su trayectoria biográfico-académica: de nacionalidad surcoreana, decidió estudiar filosofía en Alemania y desde allí escribe. Es justamente desde su cultura de origen desde donde desarrolla su posicionamiento crítico cultural. En este pequeño trabajo se dedica a establecer un contraste en términos filosófico y culturales entre los llamados "lejano oriente" y "occidente".

El libro comienza así: "en occidente lo extraño fue durante mucho tiempo objeto de violenta exclusión o apropiación (...) en la actualidad se piensa complacientemente que todos son de algún modo iguales. Así vuelve a desaparecer lo extraño en el interior de lo propio" (p. 11). Por supuesto, aquí resuena la categoría de orientalismo desarrollada por Edward Said. ${ }^{1}$ Con ella, el crítico literario palestino daba cuenta del hecho de que occidente creó una representación ficcional del oriente (en su caso, del llamado "cercano oriente") que simplifica, deshistoriza y homogeiniza una complejidad y una profundidad que se hacen invisibles. Por supuesto, los efectos de esto no se quedan en el plano de la verdad o la falsedad abstractas, sino que son mucho más perversos: esa representación se vuelve un forzamiento real de esas sociedades. La incomprensión trasmuta en violencia. Las propias élites, educadas en occidentes o transidas de éste, convierten a esa heterogeneidad compleja, en un simple "oriente" (como también lo remarcó Franz Fanon para África). ${ }^{2}$

Es quizás en ese registro hetero-occidental donde debe ubicarse el libro. En él, Han trata de acercarnos algunas particularidades de la cultura y la filosofía orientales (para el caso utiliza ejemplos sacados de China, Japón y Corea del Sur) a través de un fuerte contraste con occidente. Paradójicamente,

\footnotetext{
* Facultad de Humanidades y Ciencias de la educación-UNLP-IdIHCS. Dirección electrónica: maxigarbarino1@gmail.com

${ }^{1}$ Said, Edward, Orientalismo, Barcelona, Debolsillo, 2008.

${ }^{2}$ Fanon, Franz, Los condenados de la tierra, Buenos Aires, FCE, 2007.
} 
o no tanto, lo que realmente genera es más bien una compresión de occidente para occidentales.

Uno de los temas filosóficos que contrasta es el del ser, la esencia y la existencia (occidentales) frente a la ausencia (oriental). Si bien pasa muy rápido de un término a otro y no repara en la compleja historia occidental de esos conceptos resulta revelador su contraste con la ausencia. Totalizar nunca deja de borrar diferencias, de achatar sutilezas (de consecuencias importantes a veces) y de des-historizar, sin embargo, esta visión totalizante, si es correctamente encarada puede mostrarnos algo. Por ejemplo, "en alemán la palabra Wesen (esencia) significaba originalmente permanecer en un lugar, estadía, lo doméstico, habitar y duración" (p. 13); desde allí nos advierte Han que occidente se basa en la permanencia, en la esencia que insiste y que constituye y guarda una interioridad. Habitar es persistir y perfila un interior. La mónada, nos recuerda Han, habita en sí misma, es una casa sin ventanas (p. 15). De allí a la idea de "yo", al deseo que incorpora, le da forma yoica a lo exterior, lo interioriza. El apetito es lo que hace que el mundo (occidental) sea. El yo como la esencia es diferenciación. Es sorprendente aquí la coincidencia, no indicada por el autor, con el excursus sobre Odiseo de Horkheimer y Adorno: el yo como la astucia de dominio (razón instrumental) que le da forma a lo exterior y lo interior, administrando el deseo. Todo, claro, para volver al hogar (y ser reconocido por las huellas de su pasado). ${ }^{3}$ No es que Han no cite positivamente literatura occidental: están Barthes, Canetti y Kafka entre otros. Pero no los cita como análisis del occidente mismo, sino como punto de contacto con el lejano oriente. En fin: contra el ser, la esencia y la existencia (que subsiste, permanece, habita, se diferencia, se constituye como un interior) la ausencia. "La no esencia, la ausencia se sustrae a toda fijación sustancial" (p. 17). Han utiliza ausencia para vincular distintas vertientes del lejano oriente: "ciertamente, nos dice, el caminar taoísta no es idéntico al no habitar budista. Pero la negatividad de la ausencia conecta a ambos", de la misma manera, "un monje zen debe carecer de morada fija, como las nubes, y de apoyo firme, como el agua" (p. 18). Así, el buen caminante no deja huellas: porque no tiene peso (yo), porque no hay una dirección (sentido), mucho menos una teleología, es una procesualidad infinita. El sabio es sin yo, no tiene nombre, no convierte

${ }^{3}$ Adorno, Theodor y Horkheimer, Max, Dialéctica de la ilustración, Madrid, Trotta, 1994. 
tampoco a nada en contenido de su yo, porque no hay aquí deseo, aunque sí una vitalidad pura.

Han muestra la idea de ausencia también en acto, o, si se nos permite la referencia filosófica occidental, en algunos rasgos del ethos cultural del lejano oriente. La danza, la cocina, la práctica del saludo y el teatro de marionetas son ocasiones donde la ausencia muestra estructuras prácticas completamente heterogéneas a occidente (estructuradas por la esencia, el yo, la permanencia, etc.). Pero quizás donde mejor muestra Han el contraste es en las diferentes estructuraciones de la luz y el espacio. Si la "esencia es diferencia" (p. 38), la ausencia es in-diferencia: de ahí las transiciones más que los límites claros. En las calles de oriente, a menudo no se sabe dónde termina una casa y comienza otra, dónde termina un comercio y dónde comienza otro, en las calles del mercado es típica una yuxtaposición -casi como en la borgeana enciclopedia china- inclasificable de objetos. Del mismo modo, si para la arquitectura occidental (y para este análisis Han sigue la estética de Hegel) son centrales la diferencia entre afuera y adentro y entre luz y sombra, eso no sucede en el oriente de Han. "La belleza clásica -occidental- irradia hacia el exterior, la romántica irradia un brillo interior" (p. 40), pero, en todo caso, hay una clara separación interior/exterior que juega un papel a priori. En cambio "la espacialidad oriental se eleva por sobre la dicotomía entre abierto y cerrado, entre adentro y afuera, entre luz y sombra y genera una in-deferencia, un entre" (p. 43). Por ello la utilización característica del papel de arroz: disuelve las diferencias y la interioridad; no dirige la luz, sólo induce una transparencia suave (no desenfrenada, dice Han, como la arquitectura de cristal moderna), una difuminación.

¿Qué sería el pensamiento entonces? Aquí Han contrapone “estrategias del pensar" diferentes. En occidente "el mundo se presenta como una resistencia que hay que vencer" (p. 81), de allí la metáfora insistente (en Kant, en Hegel, pero que va desde la antigua Grecia a Heidegger) del pequeño barco y su viaje heroico. El pensamiento es la pequeña balsa, es lo firme a lo que el pensamiento, cuando es verdadero, puede aspirar y, en ella, con mapas y mucho cuidado, intentar navegar. El mar: lo mendaz, lo peligroso, lo indiferenciado. Retomando varias citas de Heidegger, Han encuentra que en occidente la estrategia del pensar pasa por "amansar las olas salvajes, puesto que se mueve en el oleaje de un mar, en el abismo de la pleamar" (p. 84). En cambio, en la estrategia oriental no hay ni balsa, ni pequeño barco, ni cisne en medio del mar 
abismal, ni fundamento, ni punto fijo. $\mathrm{Al}$ respecto Han comenta varias alegorías del pensamiento chino: un ave que es tan grande como el cielo, un pez que es tan grande como el mar. Este sobredimensionamiento indica eliminación de los límites, des-diferenciación. "A quien es grande como el mundo, nada en el mundo lo estorba o lo detiene" (p. 85), de allí que no hay nada que dominar, no hay algo falaz u oculto a descifrar, "ser grande desliga al Dasein (Heidegger) de su estructura de cuidado (...) no hay esfuerzo porque no se opone nada al mundo, porque hay una unión total con él” (p. 89).

Ya sea respecto del pensamiento, de la concepción del ser o de diferentes planos culturales, los contrastes que propone Han son más que claros y fuertes. Sin embargo, como ya indicamos, toda totalización, se haga desde donde se haga, siempre nos deja la sospecha de que deja sutilezas de lado, incluso excepciones y hasta tradiciones que no encajan en la totalización. Pero no cabe duda de que este trabajo, breve pero agudo, ayuda a pensar(nos), a explorar límites, a interesarnos por otras "estrategias".

No podemos dejar de preguntarnos por el lugar crítico de esta obra. No cabe duda de que en la intención del autor no se trata solo de poner verdad sobre falsedad (si realmente esto se pudiera hacer en un plano desconectado del mundo). La cita con la que comenzamos y la reconocida obra crítica del autor lo ubican en otro plano. Ahora bien, en este caso puntual, nos cabe preguntarnos hasta qué punto la posición lejano oriental de Han puede tener consecuencias políticas críticas. El camino sin habitación y sin huella, sin interior, el amoldarse del agua, ¿hasta qué punto pueden ser formas de vida que trasformen? Por supuesto que una forma de vida tal parecería alejada del consumismo frenético autodestructivo actual, de la exigencia de felicidad exultante y continua hasta la impostura deprimente, de la frustración autoculpabilizante sistémica, pero ¿es eso suficiente para generar una alternativa (dejando de lado la posibilidad siempre acechante de que toda esta forma se vuelva sólo una parcela de consumo como las casas de comidas rápidas adaptados a la costumbre hindú que describe $\check{Z}$ ižek)?4

Como advierte reiteradamente el filósofo Enrique Dussel, la hegemonía noroccidental es reciente, no lleva más de 200 años. ${ }^{5} \mathrm{Y}$, por tanto, construir un intercambio que reconozca las diversas formas de ser en el mundo, subsumidas

\footnotetext{
${ }^{4}$ Žižek, Slavoj, La suspensión politica de la ética, Buenos Aires, FCE, 2005.

${ }^{5}$ Dussel, Enrique, Politica de la liberación. Historia mundial y crítica, Madrid, Trotta, 2007.
} 
pero no desaparecidas por la (pos)modernidad occidental, es tan deseable como posible. Sin embargo, el solo hecho de que una cultura haya sido subsumida no la hace valorable en sí misma, sino sólo partícipe posible de un intercambio.

Recibida: 08/2020. Aceptada: 12/2020. 